\title{
Mesmo em tempos de COVID-19, não dá para lavar as mãos de Paulo Freire
}

Even in times of COVID-19, we cannot wash our hands of Paulo Freire

\author{
Aun en tiempos de COVID-19, \\ no puedes lavarte las manos de Paulo Freire
}

TIMOTHY DENIS IRELAND*

Universidade Federal da Paraíba, João Pessoa- PB, Brasil.

\begin{abstract}
RESUMO: Neste texto, argumenta-se que apesar das mudanças impostas pela pandemia da COVID-19 e as ameaças colocadas pela crise ecológica, o referencial teórico de Freire nos auxilia tanto entender o novo contexto como tecer uma nova narrativa em que a capacidade e a necessidade das pessoas aprenderem ao longo da vida sejam reconhecidos como parte constituinte da condição humana. Entre os desafios desse contexto inédito são os da saúde coletiva, da emergência climática e dos fundamentos democráticos das nossas sociedades. Não há como superar esses desafios sem uma mudança no paradigma de desenvolvimento.
\end{abstract}

Palavras-chaves: Pandemia. Crise ecológica. Aprendizagem e educação de jovens e adultos. Bem-estar planetário.

\begin{abstract}
In this text, I argue that in spite of the changes imposed by the COVID-19 pandemic and the threats posed by the ecological crisis, the theoretical framework of Freire assists us both to understand the new context and to weave a new narrative in which the capacity and necessity of people to learn throughout their lives is recognised as a constituent part of the human condition. Amongst the challenges of this context are those of collective health, the climatic emergency and
\end{abstract}

* É graduado em Letras e Língua Inglesas pela Universidade de Edimburgo, mestre e doutor em Educação de Adultos, ambos pela Universidade de Manchester. Atualmente é professor titular da Universidade Federal da Paraíba e coordenador da Cátedra da UNESCO em Educação de Jovens e Adultos. E-mail: <ireland.timothy@gmail.com>. 
the democratic foundations of our societies. These challenges will not be overcome without a change in the development paradigm.

Keywords: Pandemic, Ecological crisis. Youth and adult learning and education. Planetary well-being.

RESUMEN: En este texto se argumenta que, a pesar de los cambios impuestos por la pandemia COVID-19 y las amenazas que plantea la crisis ecológica, el marco teórico de Freire nos ayuda tanto a comprender el nuevo contexto como a tejer una nueva narrativa en la que la capacidad y la necesidad de aprender de las personas a lo largo de la vida son reconocidas como parte de la condición humana. Entre los desafíos de este contexto sin precedentes se encuentran los de la salud colectiva, la emergencia climática y los cimientos democráticos de nuestras sociedades. No hay forma de superar estos desafíos sin un cambio en el paradigma del desarrollo.

Palabras clave: Pandemia. Crisis ecológica. Aprendizaje y educación de jóvenes y adultos. Bienestar planetario.

\section{Considerações iniciais}

N esse modesto texto, pretendo criar um diálogo entre vários textos da minha autoria, alguns escritos recentemente sobre o impacto da pandemia causada pelo vírus Sars-Cov-2 e outros não tão recentes, mas, em minha opinião, ainda pertinentes, alguns escritos em inglês e outros em português. Dessa forma, sem necessariamente me referir constantemente ao opus de Paulo Freire, pretendo demonstrar a perenidade do referencial teórico deixado por ele para entender e agir sobre as novas realidades que enfrentamos no intuito de transformá-las. Com isso, não desejo elevar o referencial freireano ao status de doutrina intocável, contrário ao próprio espírito da teorização de Freire, especialmente ao enfrentar contextos inéditos como o atual, mas de reconhecer sua contribuição fundamental para o pensar e repensar da narrativa da educação, em particular a educação de jovens e adultos (EJA) ${ }^{1}$, para atender as necessidades de aprendizagem dos sujeitos jovens e adultos.

Segundo Ramón Grosfoguel (2013), o Freire original, junto com a Teologia da Libertação, possuem o grande mérito de contribuir para a crítica e o pensamento contra-hegemônico na América Latina, em que a cultura popular foi considerada central para a produção de pensamento crítico. Para fazer justiça a Freire, deveríamos entender o seu propósito de criar uma teoria de educação ou uma nova epistemologia e não um 
sortimento eclético de métodos e técnicas a serem usados quando conveniente. Enquanto contextos e alianças têm mudado e se deslocado nos últimos 50 anos, as políticas inspiradas pela ética de Freire possuem potencial para interpelar a própria base das democracias ocidentais.

Com isso, não pretendo argumentar que Freire é o único teórico, nem a educação popular a única alternativa. Existem outros paradigmas fundamentados em outras cosmologias que apresentam potencial semelhante para desafiar a lógica ocidental. O que propomos é a necessidade de um diálogo constante entre paradigmas alternativos de educação e desenvolvimento, incluindo a educação popular com base em seu bom histórico de serviços prestados. Embora haja pouca probabilidade de tais paradigmas se tornarem hegemônicos no futuro previsível, desempenham papel fundamental como desafiantes permanentes, questionadores, e contrapesos à ortodoxia estabelecida. Não existe receita para mudança, mas a crença que seja possível e que é a agência humana que move a história e não vice versa deve nos estimular a continuar buscando meios para desenvolver educação como uma prática de liberdade circunscrita a um conceito de democracia ativa e participativa.

Nos idos de 1963, a proposta de educação e alfabetização que fundamentava a experiência de Angicos suscitou uma narrativa pedagógica diferente, superadora da ortodoxia tradicional, com a ênfase no diálogo entre educador e educando e entre os saberes científico e popular. Os educandos eram concebidos e tratados como protagonistas e sujeitos do processo educativo, já que a alfabetização partia de palavras da sua vivência e de seu vocabulário. Invertendo a lógica da grande maioria de propostas pedagógicas anteriores, no caso de Angicos, os educandos junto com o seu mundo, a sua cultura e seu conhecimento se viram valorizados e respeitados. Representou uma nova compreensão de educação em que a cultura popular como projeto contra-hegemônico e a educação popular constituíram as pedras angulares de um novo sistema educacional, pensado na sua dimensão política e capaz de contribuir para a transformação da sociedade.

Em Angicos, Freire buscou, entre outros objetivos, contribuir para a formação do cidadão para uma nova sociedade democrática e participativa em construção, reconhecendo o papel fundamental de uma nova narrativa educativa nesse processo - a educação popular da qual o processo de alfabetização fazia parte.

Assim, ao dialogar com o legado de Freire para a educação de jovens e adultos, consideramos que o desafio que Freire continua nos apresentando é como desenvolver a EJA na perspectiva e no espírito da educação popular e de forma a preparar o cidadão para participar ativamente do processo democrático. Ao nos referirmos aos princípios acima, quiçá seja possível apontar alguns desafios centrais. Embora a escolaridade ainda seja um dos principais desafios da EJA, como reconstituir e valorizar a dimensão política e emancipatória desse processo? Os nossos processos de ensino aprendizagem estão ainda excessivamente mais preocupados com o ensino do que com a aprendizagem, com o 
decorar do que com o criar. Como trazer os educandos para o centro da nossa preocupação pedagógica em termos teórico-metodológicos, políticos e práticos? Num mundo ainda regido pelo neoliberalismo, pela predominância do mercado e pela influência da empregabilidade sobre os contornos da EJA que ofertamos, como estabelecer novas utopias em que os princípios de qualidade de vida, solidariedade, justiça e sustentabilidade predominem sobre os do consumismo, do individualismo e de uma visão antropocêntrica da relação do mundo natural - humano e natureza? Freire sempre nos desafia e questiona.

Ao tentar identificar os princípios fundamentais dessa narrativa popular, apontamos componentes elementares que são constantes, independentemente do contexto histórico:

1. Aprendizagem constitui uma necessidade humana fundamental que faz parte da vocação ontológica do ser humano. Incorpora o nosso DNA como animais superiores e nossa programação no sentido darwiniano.

2. Educação como processo, sujeita à agência humana, cujo objetivo fundamental é de emancipar, libertar e fazer as pessoas mais criativas. Uma educação que não se limita a transmitir, mas, sobretudo, a produzir conhecimentos como elemento constituinte da prática da liberdade. Ao pretender emancipar, a educação toma como ponto de partida o diálogo, sua ferramenta essencial.

3. Partindo da nossa 'inconclusão' como seres humanos, a educação e a aprendizagem são entendidas com processos e ferramentas que utilizamos ao longo da vida.

4. Ao recusar o pensamento fatalista (neoliberal), que nega o sonho de outro mundo possível, a utopia se torna o horizonte e verdadeiro realismo do educador. Nas palavras de Freire (1997, p. 85) “o mundo não é; o mundo está sendo”.

5. Compreende a educação no sentido amplo, abrangendo o que se tem convencionado como educação formal e não formal, em que a escola não é o único espaço da veiculação do conhecimento (FREIRE, 1991, p. 16) e, consequentemente, se caracteriza como um processo que envolve tanto lógica e intelecto, quanto afeto e sociabilidade.

6. Trata-se de uma educação que valoriza a experiência cotidiana e coloca qualidade de vida/ bem-estar/felicidade coletiva dos sujeitos como meta: a vida como o último currículo.

7. Uma educação como ato político intencional, que busca a emancipação e pressupõe um projeto de sociedade. Uma pedagogia comprometida com a cidadania ativa e a participação política. 
8. Uma educação que valoriza e procura aprofundar a democracia, posicionando a ética como referencial central da busca pela sua radicalização.

9. Uma educação em que a vida constitui o ponto central convergente e o elemento unificador, a característica comum de toda existência humana, animal, vegetal e natural.

10. A ecossustentabilidade constitui a premissa para uma vida planetária saudável.

Acreditamos que o modelo de educação de jovens e adultos - o que chamamos de modelo deficitário -, e agora falamos especificamente do Brasil com alguma ressonância para os outros países da América Latina, se esgotou. Apesar do discurso progressivo (as referências a sustentabilidade, a educação e aprendizagem ao longo da vida, a cidadania), a prática, em termos gerais, apresenta uma educação compensatória com um forte viés escolar. Ao examinar o informe brasileiro para o II Relatório Global de Aprendizagem e Educação de Adultos (Grale da sigla em inglês ${ }^{2}$ ), sentimos a ausência de uma perspectiva mais inclusiva do que se entende por educação de adultos ${ }^{3}$. Estruturalmente, a EJA é disciplinar e compartimentalizada, bastante inflexível (apesar da flexibilidade que a LDB permite) no quesito curricular e temporal e preocupada com certificação. Mas, talvez, de todas as suas deficiências, o que mais distancia os sujeitos dos programas em oferta é a irrelevância dos conteúdos para a vida das pessoas. Existe um divisor desafiante entre a vida escolar e a vida cotidiana dos sujeitos: os conteúdos escolares se tornam uma excrescência para a vida do/a trabalhador/a. Por último, a agenda da EJA se caracteriza por ser uma ferramenta que procura reduzir e corrigir índices negativos: reduzir a pobreza, erradicar o analfabetismo (sic), reduzir a desigualdade (entre rico e pobre, branco e negro, indígena e branco, homem e mulher, Nordeste e Sul, campo e cidade), corrigir o fluxo escolar, elevar índices baixos de escolaridade, diminuir a iniquidade, buscando aumentar a inclusão social. Julgamos que exista um risco pronunciado de reforçar o processo de desumanização, e não de realizar e desenvolver o potencial humano para ser mais.

Qualquer busca para o novo necessariamente referencia-se pelo velho que procura ultrapassar. Assim, uma nova narrativa de EJA, pós-COVID, pode continuar tendo uma articulação forte com as demandas do mercado de trabalho, porém, com um mercado de trabalho cujas orientações incluem a necessidade de assumir uma postura de sustentabilidade voltada para uma compreensão da fragilidade do ecossistema amplamente evidenciada pelas mudanças climáticas. Nessa busca, compreende-se a educação não apenas como um processo lógico e intelectual, mas também como um processo profundamente afetivo e social que interage com a vida das pessoas, em termos temporais (educação e aprendizagem ao longo da vida e na dimensão histórica), em termos da diversidade e pluralidade dos sujeitos (mulheres e homens que vivem nos mais diversos contextos orientados por distintas visões cosmológicas e religiosas), em termos de 
conteúdo (aprender é viver: vida como último currículo), em termos de qualidade de vida (bem-estar e bem viver humanos, dentro da perspectiva da ecossustentabilidade e da convivência planetária como objetivos centrais de qualquer política de desenvolvimento) e em termos transformativos e emancipatórios (aprendizagem como uma necessidade humana fundamental e parte da nossa vocação ontológica).

Na continuidade, me proponho a discutir brevemente o contexto que antecedeu a chegada dessa última pandemia, COVID-19 - não é a primeira pandemia do século XXI - e a situação em que encontrou a educação de jovens e adultos no Brasil. Em seguida, pretendo discutir a natureza dessa pandemia e porque considerá-la um desafio educacional para depois colocar três temas que me parecem centrais ao buscar construir uma nova narrativa para a EJA, na medida em que saímos do auge da crise: a relação entre saúde e educação e, especialmente, EJA e saúde preventiva; a questão da crise ecológica; e o que Harari (2020) chama do "grande teste para a cidadania" - fortalecer o empoderamento cidadão junto com a solidariedade global ou sucumbir à onda de populismo nacionalista.

\section{Da retórica à ação? A EJA pós-Belém}

Às vezes, temos memórias convenientemente curtas. Há apenas onze anos, em maio de 2009, o Brasil se preparava para realizar a VI Conferência Internacional de Educação de Adultos (VIConfintea), em Belém do Pará. A Confintea teve que ser adiada até dezembro daquele ano por motivo da pandemia causada pelo novo vírus de influenza H1NI, a primeira pandemia do 21ํㅗ́culo (entre 2009 e 2010 mais de 200 países registraram casos confirmados desse vírus). Essa primeira pandemia aparentemente teve pouco ou nenhum impacto sobre a nossa compreensão do papel da aprendizagem e educação de adultos em tais situações de emergência. Para a maioria dos delegados, pelo menos, foi uma inconveniência que perturbou os planos de viagem.

Apesar do prenúncio que o H1N1 propiciou e apesar de sucessivas epidemias de dengue, zika, chikungunya, febre amarela, tuberculose, sarampo etc., o País tem se preparado minimamente em termos educacionais para o impacto desses vírus sobre a população em geral. A falta de preparo educacional e informacional das pessoas sobre como assumir um nível básico de responsabilidade para a sua saúde individual, coletiva e comunitária tem sido gritante. Em geral, nossas políticas públicas de saúde dedicam a maioria do orçamento para medicina curativa e não para medicina preventiva (Lopes, 2018).

O contexto que o Coronavírus encontrou no Brasil foi o de um desinvestimento brutal na EJA nos últimos dez anos. Em 2012, o Governo investiu R\$1.6 bilhões em EJA. Em 2019, o MEC gastou R \$16,6 milhões, o que correspondia a 22\% do orçamento previsto (R\$71,0 milhões). Em 2012, o gasto em EJA representava 4,74\% do gasto total em educação. Em 2019, essa porcentagem caiu para 0,21\%. O orçamento previsto para a EJA em 
2020 é R\$25 milhões. E isso, em um país em que há ainda 11,3 milhões de pessoas analfabetas e 77 milhões de jovens e adultos de 18 anos ou mais sem terem concluído o ensino obrigatório, das quais somente 3 milhões estejam matriculados na EJA. Nesse contexto, os dados sobre a EJA se restringem às matrículas em programas de alfabetização e no ensino fundamental e médio, ofertados por governos estaduais e municipais e financiados com recursos do Fundeb. Quase todos os programas e projetos de abrangência nacional financiados pelo Governo Federal deixaram de funcionar: o Programa Brasil Alfabetizado, o Projovem, o Proeja, Pronatec etc. Dados sobre o que chamamos no início do artigo de "uma perspectiva mais inclusiva do que se entende por educação de adultos" - a dimensão não-formal e não escolar - são mais difíceis de projetar.

\section{Entender a origem e o impacto da pandemia}

O sucessor do H1N1, o Sars-Cov-2 (cabe lembrar que esse nome se refere ao vírus que causa a doença infecciosa que se chama COVID-19), tem tido um impacto mais profundo, interferindo em todas as dimensões da vida "normal" - social, cultural, religiosa, econômica, educacional, recreativa e esportiva. H1N1 e Sars-Cov-2 são considerados agentes patogênicos de origem zoonótica, isto é, passam de animais para humanos. Como Zanella (2016) anota:

\footnotetext{
os fatores para a emergência ou a reemergência de doenças são pouco conhecidos e entendidos, mas o principal é a expansão da população humana. Outros fatores incluem mudanças climáticas, globalização e intensificação da produção animal. Isto é preocupante, já que $75 \%$ das doenças humanas emergentes ou reemergentes do último século são zoonoses, isto é, doenças de origem animal, que, além de causarem fatalidades humanas e animais, afetam a economia de países (s/p).
}

Zanella aponta para a tensão especialmente prevalente durante a atual pandemia entre os impactos econômico e sanitário sobre a vida da população. Essa tensão levou o Cardial Michael Czerny (2020) a perguntar: "a pandemia é uma crise 'global' porque todos os países da terra foram expostos ou estão sofrendo dela? Ou porque, num mundo dominado por uns poucos países ricos e poderosos, essas são as nações a serem atingidas primeiro e de uma forma especialmente dura?".

Embora as teorias de conspiração tenham fabricado outras possíveis explicações para a emergência do novo Coronavírus em Wuhan (China), a maioria dos estudos rigorosamente científicos aponta para o impacto da atividade humana nos habitats da vida selvagem como a explicação mais viável pela atual pandemia. Inclusive, indicam que o processo de desmatamento na Região Amazônica levará inevitavelmente ao surgimento de novos e igualmente perigosos vírus. Em outras palavras, a atual pandemia se relaciona com dois fenômenos centrais - a questão da saúde pública e a da crise ecológica. 
Apesar do impacto do primeiro, não podemos esquecer o segundo, ao considerar qual seria o vínculo da aprendizagem e educação de adultos com tais assuntos. Podemos, talvez, acrescentar uma terceira questão central - presente na pergunta do Cardial Czerny, que aparentemente determinou a política pública em diversos países: a importância relativa da vida humana versus a da atividade econômica. Podemos perguntar qual, em geral, causa mais impacto - uma queda no PIB ou uma queda no IDH?

Isso nos leva a perguntar quais seriam as funções potenciais da EJA numa crise dessa natureza? E seriam diferentes das funções da EJA em tempos de normalidade? Se colocamos a vida humana e o equilíbrio essencial entre o meio ambiente humano e o meio ambiente natural no cerne das nossas preocupações, a EJA deveria se preocupar com o bem-estar de todos os seres humanos, o que inclui a dimensão fundamental da nossa saúde coletiva e como aquele é ou não é tratado pelas sociedades em que vivemos. Bem-estar não pode ser reduzido à dimensão puramente materialista, mas deveria incluir a qualidade de relações humanas coletivas e o direito a saúde: saúde como pré-requisito para a vida e vida como pré-requisito para a educação. Assim, discussões sobre o vírus e suas implicações, disponibilizando conhecimento científico sobre a doença e sobre como nos proteger são todos assuntos essenciais. No entanto, precisamos também relacionar isso à mudança climática e como ela impactará em nossas vidas e para a questão igualmente importante da democracia e governo democrático. A sociedade se baseia numa série de pesos e contrapesos. A EJA pode fazer parte desses pesos e contrapesos, ao formar cidadãos críticos e questionadores para participar ativamente da sociedade.

\section{EJA e pandemia aparentemente não rimam}

Pelo menos no mundo em desenvolvimento, a pandemia serviu para demonstrar a falsidade da noção de que habitamos num mundo interconectado em que comunicação fácil e rápida seja acessível para todos. $\mathrm{O}$ acesso às tecnologias de informação e comunicação é tão desigual quanto a distribuição de renda. A grande maioria de adultos e jovens que compõe o público da EJA são aqueles que não possuem acesso às TIC. Portanto, precisamos repensar nossas estratégias de entrega para a EJA. Como melhor alcançar os que mais precisam da EJA? Isso significa levar a EJA a onde o público potencial vive ou de garantir acesso à internet gratuitamente por meio de centros comunitários. Alternativamente, whatsapp ou aplicativos semelhantes podem ser usados para oferecer uma via de mão dupla entre educador e educando, sem esquecer o potencial enorme do rádio. Muitos programas educativos para adultos de grande sucesso foram baseados na transmissão por rádio no passado. 


\section{Mudando a narrativa da EJA}

As agressões e a relação predatória com o meio ambiente, em que a natureza é considerada como um objeto apenas para satisfazer as necessidades humanas, começam a ser questionadas quando o mundo natural dá sinais de esgotamento, de não suportar mais. Nesse sentido, a pandemia da COVID-19 deve ser considerada mais um dos sinais e, como Santos argumenta (2020, p.31), “(...) se a vida humana continuar a pôr em causa e a destruir todas as outras vidas de que é feito o planeta Terra, é de esperar que essas outras vidas se defendam da agressão causada pela vida humana e o façam por formas cada vez mais letais". Os nossos termos de referência dominantes são essencialmente antropocêntricos e frequentemente apenas eurocêntricos ou, no máximo, ocidentais.

A pandemia da COVID-19 tem demonstrado a incapacidade completa das políticas neoliberais de lidar com esse nível de crise social e econômica. Tem demonstrado, igualmente, as falhas do modelo atual de globalização. Recentemente, a narrativa da EJA tem sido construída em torno desses pilares com o foco obcecado pelo mercado e qualificação e requalificação para o emprego. A EJA, agora, tem a oportunidade de escrever uma nova narrativa, em que se valoriza a vida humana acima de valores econômicos e materialistas puramente individuais e cooperação acima de demandas individuais. Está na hora, uma vez para sempre, de enterrar as palavras trágicas de Margaret Thatcher de que "Não há sociedade, somente indivíduos" - a negação da essência da humanidade.

Vários anos atrás, Ivan Illich argumentou que:

nem revolução nem reforma pode ultimamente mudar uma sociedade, mas bem se deve contar uma nova história poderosa, tão persuasiva que apague todos os velhos mitos e se torna a história preferida, uma tão inclusiva que junta todas as peças do nosso passado e de nosso presente num conjunto coerente, um que até joga luz sobre o futuro para que possamos dar o próximo passo... Se você quiser mudar a sociedade, há de contar uma história alternativa (apud SPRINGER, 2016, p.2).

Se a EJA quiser contribuir para mudar a sociedade, o desafio é de "contar uma história alternativa", que incorpora os desafios a serem enfrentados ao tempo em que aponta para as ferramentas conceituais e a bagagem teórico-metodológica já acumuladas no campo. $\mathrm{O}$ conceito da educação e aprendizagem enquanto processo que acompanha a pessoa adulta ao longo e ao largo da sua vida é central. Entre os elementos que essa nova narrativa terá que incluir destacamos três que se impõem como urgentes no presente contexto: a relação entre saúde coletiva e educação e, especialmente, EJA e saúde preventiva; a questão da crise ecológica; e o que Harari chama do grande teste para a cidadania - fortalecer o empoderamento cidadão junto com a solidariedade global ou sucumbir à onda de populismo nacionalista. Trataremos de cada uma dessas temáticas de forma separada, mesmo reconhecendo que as três são intrinsicamente articuladas. 


\title{
Educando para a saúde
}

De acordo com Lopes (2018), “a educação de adultos constitui uma ferramenta fundamental para promover a saúde e consolidar um novo paradigma que reforce a atenção sanitária mediante a gestão do conhecimento". A medicina preventiva é, em grande parte, um processo educativo em que as pessoas aprendem a tomar responsabilidade para a sua própria saúde. Em média, na divisão dos orçamentos nacionais para saúde, a medicina curativa recebe em torno de $98 \%$ dos recursos, reservando os restantes $2 \%$ para a medicina preventiva. que consiste em geral de campanhas de massa de vacinação (Lopes, 2018). Embora vários países, incluindo o Brasil, tentem reduzir o foco da educação de jovens e adultos para a dimensão de escolarização tardia, são acontecimentos como o atual que revelam a miopia dessa visão. O potencial e a versatilidade da EJA residem na sua natureza intersectorial e interdisciplinar.

Da mesma forma que hoje em dia se considera a alfabetização como um contínuo e não como uma etapa inicial do processo de escolarização, Lopes argumenta pela necessidade desse processo de educação para a saúde acompanhar a pessoa ao longo da vida:

así pues, la alfabetización para la salud se convierte en un proceso de educación que debe extenderse desde el principio hasta el final de la vida, y en el cual cada etapa requiere una formación específica, ya sea respecto de las funciones sociales que le corresponde cumplir a cada persona, ya sea con relación a las necesidades específicas que los individuos deben satisfacer (Lopes, 2018:17).

E completa:

\begin{abstract}
en resumen, los ciudadanos que han recibido una adecuada formación en materia sanitaria tienden a adoptar estilos de vida más saludables, a disfrutar de una mejor salud mental y a incurrir en menos comportamientos riesgosos. Cuando se presenta una enfermedad, son pacientes o cuidadores que suelen reaccionar en las etapas más tempranas de la afección, con lo que logran mitigar los casos más graves al intervenir cuando es más fácil controlar la situación (Lopes, 2018:19).
\end{abstract}

Isso se aplica ao adulto comum assim como aos profissionais da saúde. A pandemia da COVID-19 deixou exposta na maioria dos sistemas de saúde a completa falta de treinamento dos profissionais de saúde para enfrentar uma emergência dessa natureza.

\section{A pandemia como sintoma da crise ecológica}

Tratar a pandemia separada da questão da crise ecológica é um erro. Como Santos afirma, a crise da pandemia do novo Coronavírus constitui uma crise dentro de outra crise ainda mais grave, que não tem recebido a mesma resposta emergencial que a COVID. mas pode ter consequências mais drásticas ainda para o futuro do planeta -a 
crise climática como parte de uma possível catástrofe ecológica. Como Santos lembra, de acordo com a Organização Mundial de Saúde, a poluição atmosférica, que constitui somente uma das dimensões da crise ecológica, mata sete milhões de pessoas anualmente. No entanto, embora a atual pandemia possa ser controlada, até a descoberta de uma vacina, por processos de educação - nos termos de Lopes, as pessoas tomando responsabilidade novamente para a sua saúde - a reversão da crise climática exige uma mudança de paradigma (uma mudança no modelo de sociedade e de desenvolvimento). Crises e pandemias são momentos de acelerada aprendizagem - aprendizagem como estratégia de sobrevivência humana. No auge (agosto de 2020), não há como saber se essa pedagogia do vírus significará o início de mudanças mais profundas na compreensão do nosso lugar no mundo e nossa relação com o planeta. Como Santos disse:

Superaremos a quarentena do capitalismo quando formos capazes de imaginar o planeta como a nossa casa comum e a Natureza como a nossa mãe originária a quem devemos amor e respeito. Ela não nos pertence. Nós é que lhe pertencemos. Quando superarmos esta quarentena, estaremos mais livres das quarentenas provocadas por pandemias. (2020, p.32)

A própria pandemia de COVID-19 não é uma externalidade mas um organismo do planeta, um vírus que lança um ataque “à forma de vida insustentável que adotamos por livre escolha (...)" (p.6.): um exemplo vivo talvez do que o poeta inglês Tennyson chamou de "Nature, red in tooth and claw" (A Natureza sangrenta em dente e unha). O argumento de Santos é reafirmado pelo líder indígena Ailton Krenak. No seu texto O amanhã não está à venda, publicado em abril de 2020, Krenak volta a criticar o que ele chama de "esse pacote [...] de humanidade" cujo estilo de vida resulta no seu descolamento do organismo que é a Terra, "vivendo numa abstração civilizatória que suprime a diversidade, nega a pluralidade das formas de vida, de existência e de hábitos". Em lugar de endeusar o mercado e, em múltiplos casos, colocar a saúde do mercado antes da saúde dos seres humanos, precisamos reconhecer o mercado pelo que ele é: um construto humano inventado por nós e que depende de nós.

\section{A educação como grande teste da democracia}

Uma análise menos "radical" (no sentido original da palavra) mas igualmente ameaçadora é apresentado por Yuval Harari, o historiador israelense. No livro Homo Deus (2017), Harari identifica três grandes ameaças para o futuro da humanidade: a ameaça nuclear, procedente da produção de energia ou armas nucleares, as mudanças climáticas, e os transtornos causados pelas mudanças tecnológicas, especialmente a inteligência artificial. Porém, ao escrever especificamente sobre a pandemia do Coronavírus, numa entrevista publicada originalmente no jornal Financial Times, em 2020, ele classifica a 
pandemia como o grande teste da cidadania, apontando duas escolhas fundamentais. A primeira se refere à implantação de ferramentas de vigilância em massa, especialmente nos países em que sempre foram questionadas e rejeitadas como parte da batalha para garantir o que resta da nossa privacidade. O oposto dessa escolha seria o empoderamento do cidadão, que, com base no acesso a informações científicas e outras informações de fontes e autoridades públicas confiáveis, teria os elementos para tomar suas próprias decisões. Como Harari coloca: “Nos próximos dias, cada um de nós deve optar por confiar em dados científicos e especialistas em saúde em detrimento de teorias infundadas da conspiração e de políticos que só servem a si mesmos".

A segunda escolha fundamental será entre o que ele chama de "isolamento nacionalista e solidariedade global”. Mesmo os países pouco afetados pela COVID-19 (Cuba, Uruguai, Costa Rica) sofrerão os efeitos da recessão econômica global. A maioria enfrentará os efeitos da pandemia e da crise econômica. Tanto uma pandemia (uma doença afetando um grande número de pessoas que atravessa fronteiras nacionais, do grego pandemios = todo o povo) quanto a economia são, por definição, problemas globais. Nenhum país sozinho conseguirá resolver as duas crises, inclusive porque a própria pandemia já é uma consequência da terceira crise global - a crise climática. A única forma para efetivamente enfrentar essas crises é por meio da cooperação global.

As conclusões a que Harari chega são, primeiro, que

\begin{abstract}
quando as pessoas são informadas dos fatos científicos e quando as pessoas confiam nas autoridades públicas para lhes informar esses fatos, os cidadãos podem agir corretamente, mesmo sem um Big Brother vigiando por sobre seus ombros. Uma população motivada e bem informada é geralmente muito mais poderosa e eficaz do que uma população ignorante e policiada $(2017, \mathrm{~s} / \mathrm{p})$.
\end{abstract}

E, segundo, que "a humanidade precisa fazer uma escolha. Iremos percorrer caminho da desunião ou adotaremos o caminho da solidariedade global?".

Em ambos os casos, a educação, a confiança na ciência, nas autoridades públicas e na mídia são fundamentais. O argumento de Harari encontra respaldo em Santos (2020, p.7), que cita evidências do periódico The Economist, segundo o qual as epidemias tendem a ser menos letais em países democráticos devido à livre circulação de informação. Assim, a saída das crises dependerá em grande parte de uma educação que se preocupa com a saúde e a vida da população, com os seus direitos humanos e civis e com o seu compromisso com os fatos, a ciência e o bem-estar da coletividade.

\title{
Lições da pandemia
}

Apesar da pandemia ser reconhecida como uma crise múltipla, também precisa ser compreendida como um presságio, anunciando crises piores se não houver mudanças 
radicais na desequilibrada relação humano x natureza. A pandemia causada pelo vírus Sars-Cov-2 é o produto da relação perversa do ser humano com a natureza. Os cientistas avisam que tanto há probabilidade de outras pandemias quanto de desastres maiores se não mudamos a relação com a natureza de onde surgiu o vírus, em primeiro lugar. Mudar a nossa relação com a natureza significa uma mudança de paradigma de desenvolvimento. Não existe uma engenharia para fazer o presente modelo predatório de desenvolvimento "sustentável". Mas, "sustentável" para quem?

É nesse contexto que o debate sobre o futuro da educação de pessoas jovens e adultas se dará. É um debate que não pode centrar-se na economia (e claramente também não pode ignorá-la) senão na vida nas suas múltiplas expressões que exige condições necessárias para florescer que, no caso do ser humano, exigirão que todos os seres humanos tenham o direito de exercer sua capacidade inerente de aprender.

Embora tenhamos, em nível global, duas agendas internacionais aprovadas em 2015, parece que a lógica subjacente ao Marco de Ação Educação 2030 e à Agenda 2030 de Desenvolvimento Sustentável continua sendo ocidental e neoliberal. Essas agendas, embora prometam a redução da pobreza mundial, farão pouco para interpelar ou transformar as relações de poder existentes e as estruturas de opressão que contribuem para manter oportunidades desiguais de desenvolvimento e, também, acesso desigual a oportunidades educacionais. Embora o direito a educação tenha se tornado um refrão consensual, há de se questionar: qual educação? Refere-se a uma educação cuja função principal é de instrumentalizar o processo de desenvolvimento ou, nos termos de Freire, uma educação como prática de liberdade?

O contexto atual demonstra com força que aprendizagem e educação de pessoas adultas é mais necessária que nunca e, sem ela, a luta para superar os novos desafios da nossa civilização será quase impossível. O conceito, nas suas múltiplas formulações, que reconhece a capacidade e a necessidade das pessoas aprenderem ao longo da vida constitui um reconhecimento de parte da nossa condição humana - viver e aprender não podem ser separados - e um reconhecimento de que esse processo de aprendizagem e educação tem que ser fomentado ao longo da vida. Em sociedades profundamente desiguais como a nossa, não podemos permitir que a distribuição de oportunidades de aprendizagem seja ditada por mecanismos como o mercado. Ao reescrever a nossa narrativa, vale a pena relembrar as palavras do ex-presidente Barak Obama, na recente convenção democrata nos EUA:

A democracia nunca foi feita para ser transacional - você me dá seu voto; eu faço tudo melhor. Requer uma cidadania ativa e informada. Por isso, também peço que acreditem em sua própria capacidade - de abraçar sua própria responsabilidade como cidadãos - para garantir que os princípios básicos de nossa democracia perdurem (OBAMA apud HEER, 2020, s/p). 
Ao escrever a nova narrativa da EJA, os desafios já estão postos: a saúde como uma questão de educação e de prevenção e não somente da medicina curativa, a crise ecológica que coloca em evidência a importância da diversidade de vida e a forma em que nos organizamos para viver em sociedade. A esses desafios, precisamos acrescentar a tarefa do que Illich chama de "junta(r) todas as peças do nosso passado e de nosso presente num conjunto coerente". Temos uma história rica em práticas alternativas de educação. No final da década de 1950, começo da década de 1960, Paulo Freire se valeu de "todas as peças do nosso passado" para reescrever a narrativa da EJA. Com a sua inspiração, a tarefa de tecer uma nova narrativa é urgente.

Recebido em 20/08/2020. Aprovado em 30/08/2020.

\section{Notas}

1. O termo mais usado no Brasil. Em outros países da América Latina o mais comum é usar Educação de Pessoas Jovens e Adultas. Na Europa o termo Aprendizagem e Educação de Adultos (Adult Learning and Education - ALE) vem se consagrando.

2. http://uil.unesco.org/fileadmin/download/en/national-reports/latin-america-and-caribbean/Brazil.pdf

3. Desde a Recomendação de Nairóbi de 1976, aprofundada na Declaração de Hamburgo em 1997, a Unesco considera que a educação de adultos engloba "Todo processo de aprendizagem, formal ou informal, em que pessoas consideradas adultas pela sociedade desenvolvem suas capacidades, enriquecem seu conhecimento e aperfeiçoam suas qualificações técnicas e profissionais, ou as redirecionam, para atender suas necessidades e as de sua sociedade" (UNESCO, 2010, p.5).

\section{Referências}

CZERNY, Michael. There is no solution without you. New Thinking for a New World: a Tällberg Foundation Podcast, Stockholm, 2020. Disponível em: https://mailchi.mp/tallbergfoundation.org/there-isno-solution-without-you?e=a3c1851d28

FREIRE, Paulo. Pedagogia da autonomia: saberes necessários à prática educativa. São Paulo: Paz e Terra, 1997.

FREIRE, Paulo. A educação na cidade. São Paulo: Cortez, 1991.

GROSFOGUEL, Ramón. “Hay que tomarse en serio el pensamiento crítico de los colonizados en toda su complejidad" - Entrevista realizada por Luis Martínez Andrade. Metapolítica, Puebla, v. 17, n. 83. P. 38-47, oct./dic., 2013.

HARARI, Yuval N. Homo Deus: A Brief History of Tomorrow. London: Vintage, 2017. 
HARARI, Yuval N. O Mundo após o Coronavírus. Tradução de César Locatelli. Carta Maior. 23 de março de 2020.

HEER, Jeet. A nobre lição cívica de Obama exige demais de nós. Carta Maior, 21/08/2020.

IRELAND, Timothy D. Paulo Freire's legacy for Youth and Adult Education in Brazil. Andragogical Studies: Journal for the Study of Adult Education and Learning, Belgrade, n. 2, p. 77-84, dec. 2014.

IRELAND, Timothy D. Adult Learning and Education for a better life, decent work and a healthy planet. DVV International, 2020.

IRELAND, Timothy D. Even in times of COVID-19, you cannot wash your hands of ALE. DVV International, 2020.

IRELAND, Timothy D. A EJA no Brasil em tempos de excepcionalidade causada pelo COVID-19. CEAAL, 2020.

IRELAND, Timothy D. Uma releitura da Educação Permanente a partir da América Latina: um capítulo inacabado. 2020, [no prelo].

KRENAK, Ailton. O Mundo não está à venda. São Paulo: Cia das Letras, 2020.

LOPES, Henrique. "How adult education can save your life". Role and Impact of Adult Education, Bonn, n. 85, p. 18-20, 2018.

SANTOS, Boaventura de Sousa. A cruel pedagogia do vírus. São Paulo: Boitempo, 2020.

SPRINGER, Simon. The Discourse of Neoliberalism. London: Rowman \& Littlefield, 2016.

UNESCO. $2^{\text {nd }}$ Global Report on Adult Learning and Education. Hamburgo: UIL, 2013.

ZANELLA, Janice Reis Ciacci. Zoonoses emergentes e reemergentes e sua importância para saúde e produção animal. Pesq. Agropec. Bras. Brasília, v.51, n.5, maio de 2016. 